\title{
Study on Strategies of Technology to Penetrate Emotional Education into Modern Education
}

\author{
Haiyan Wang ${ }^{1, a}$, Xiwu Shao ${ }^{2, b}$ \\ ${ }^{1}$ Higher Education Research Institute, Jilin Agricultural University, Changchun, China, 130118 \\ ${ }^{2}$ College of Administration, Jilin Agricultural University, Changchun, China, 130118 \\ ${ }^{\mathrm{a}}$ email, ${ }^{\mathrm{b}}$ email
}

\begin{abstract}
Keywords: Modern Educational Technology, emotional education, Healthy Personality
\end{abstract}
\begin{abstract}
Modern educational technology in education, the traditional education ideas and concepts, teaching model had a strong impact. Students in a particular physiological and psychological developmental stages, are susceptible to outside influences, and therefore in the teaching process of education, emotional education should permeate modern educational technology, imperceptibly stimulate students' motivation to learn, encourage students to have a positive and correct emotional experience to help students develop a healthy personality.
\end{abstract}

\section{Introduction}

With the gradual improvement and popularity of multimedia technology and the Internet, modern educational technology gained rapid development, and promote the study and research of modern educational technology boom theory, application methods, and promote and deepen the theoretical exploration and practice of education reform, which enrich the content of education modernization practice. Modern Educational Technology and the commanding heights of the status of education reform as a breakthrough, has gradually been widely accepted and profoundly change the traditional ideas, concepts and teaching mode of education, to promote education towards globalization, information technology, Lifelong other direction and progress.

Emotional education as an important part of the educational process, it is always concerned about the education of students in the process attitude, emotions, feelings and beliefs and other factors. Emotional education is to focus on human emotion foster education as the entry point, concerns the fundamental role of emotions in human development and a positive impact, and the use of mechanisms and emotional conditions, looking for ways to make the quality of emotional support in the moral, intellectual, physical, development of the United States, labor and other aspects of quality [1]. Therefore, in the modern educational technology is widely used in all aspects of education and teaching situation, it is necessary to fit the depth of the problem in-depth study of modern educational technology and emotional education, help educators to establish a correct ideological and concepts of education, in order to ensure modern education the value and role of technology to be fully realized and play, to achieve human freedom and comprehensive development.

\section{A Modern Educational Technology to Infiltrate Affective Education Inevitability}

In 1978, Comrade Deng Xiaoping at the National Education Conference, said: "To develop measures to accelerate the development of modern means of education television, radio, etc., it is an important way to better and more economical development of education must be given sufficient attention." 1999 , the State Council promulgated the "CPC Central Committee and State Council on deepening education reform and promote quality education", said: "vigorously raise the level of modernization of education and the degree of information technology in education, building to China Education and Research network and satellite video system based on modern distance education network, strengthen the construction of economical and practical type terminal platform 
system and campus networks or local area network, make full use of existing resources and a variety of audio-visual means, continue to do well diversified audio-visual education and computer-aided instruction. "State Council approved the Ministry of Education in 1999," 21st century Education revitalization action plan "that:" relying on modern distance education network set up high-quality online courses, organization of national-class teachers were taught to achieve educational resources across time and space shared". In October 2000, the Chinese Ministry of Education held a "national primary and secondary IT Education Conference" in Beijing, we decided since 2001, with about 5-10 years in primary and secondary schools nationwide basic common information technology education, the full implementation of "School school through engineering. " July 2010, Hu Jintao at the National Education Conference noted that "we must take educational information to promote the modernization of education, the education information into national information technology development overall strategy to accelerate the educational information infrastructure, ahead of the deployment of education information network to enhance quality education development and application of resources to build the national education management information system to ensure that by 2020 basically completed education information system covering urban and rural schools at all levels to promote the sharing of universal quality education resources, accelerate the popularization and application of information technology for All. "State full attention to educational technology, information technology and curriculum integration teaching phase, educational information to promote the modernization of education education development strategy to promote the government, the school of modern educational technology hardware and software investment, modern technology education and emotional education deep integration provided policy support.

Modern educational technology is based on modern educational ideas, theories and methods as the basis, the system theory as a guide to modern information technology as a means of educational technology, where "Modern Information Technology" includes computer technology, digital audio and video technology, electronic communications technology, network technology, satellite radio technology, telecommunications technology, artificial intelligence, virtual reality simulation technology and multimedia technology and information highway. Modern educational technology through modern information technology to provide audio for learners, colored, rich and vivid learning tangible images, effectively stimulate learner motivation, enhance the learner's desire to learn. Emotional education is also inherent in that arouse students' interest in learning, to create conditions to ensure that each student has a successful experience in the learning process, improve the quality of their creativity. Therefore, modern education technology to provide students with a new information platform, providing great convenience to communicate with others, to expand the students' learning space for students to enrich knowledge, improve their own offers the potential to provide an effective affective education implementation platform.

The purpose is to train school for social development needs of the various types of personnel. In the knowledge economy, schools have realized the importance of modern educational technology into teaching, and therefore, the development of all types of schools in developing modern educational technology-related rules and regulations, and increased hardware investment modern educational technology, such as the establishment of education technology (network) center, and actively building digital campus, digital library, actively encourage teachers to create multimedia courseware, instructional videos and other open development network. School of modern educational technology hardware and software investment, for carrying out the emotional education to provide convenient conditions.

The development of modern information technology to provide students with a completely open, broad and rich sources of information, students are free to acquire any knowledge, for more information. But the network is a virtual, unreal world, everyone exists on the network is virtual, digital, appears in symbolic form, the interaction between people and also the performance of the interactive symbol symbol. Internet people are missing, "the presence of others," the pressure, "the pleasure principle" dominates the personal aspirations of everyday life repressed the evil side of human nature in this stress-free and low state constraints and give vent, so that the students 
reducing moral self-discipline, ethical misconduct, the role of the lost self. Complex content on the Internet, many Spirit "foreign" garbage full of them, because of the openness of the Internet features, these spirits refuse unimpeded reach college students computer screen directly toxic to the thought of the young generation, resulting in students moral online weakening affect their real life ethical behavior. As students in a particular physiological and psychological developmental stages, are susceptible to outside influences. The students go to such values when dealing with others will inevitably bring about exchanges extreme. At the same day students indulge in the network, easy to form interpersonal disorder, autism, Love mesh network addiction psychosis syndrome [2]. The negative impact of modern information technology is inevitable, but also to find a realistic basis for the strengthening of affective education.

\section{Modern Educational Technology to Infiltrate Affective Education Ways}

To play an active role in the modern educational technology, teachers should strive to tap the teaching content rich emotional factors to strengthen the students' emotional influence, improve students' aesthetic taste, and foster students' personality.

In a globalized, networked era context, modern educational technology plays for the national culture in line with a political taste, with some technical capacity of mission personnel [3], the emotional education as an important part of a complete education, its connotation is concerned, it is not a teaching method, but an educational concept, an educational concept [4], aimed at promoting culture through respect for social and emotional quality of students, develop their emotional self-control ability in the education process, they all learn, live in and around a positive emotional experience, to form an independent sound personality and personality characteristics, and promote the healthy and harmonious development of individual students and the entire community. Educational technology in education can not only bring positive value of education, but also bring a negative value. Thus, educators in the use of modern educational technology, you must update the concepts of education, technology keep a clear head, a clear understanding of the technology itself has value judgments bias, abandon the "instrumental rationality", adhere to the principles of education educational technology, to strengthen their own humanism accomplishment, to promote the comprehensive development of students for the purpose of strengthening the humanities education in the field of educational technology.

Rogers said: teaching is a process of emotional activity, the purpose of education is to stimulate students' motivation to learn, develop the potential of students, to enable students to form a positive self-concept and value system, to encourage students to become "fully human." Educators praise Markov said, "interest in what they learn may be the motivation to learn," Bruner also raised "the best stimulus to learning is the learning materials of interest." "Public Relations" course, in order to promote active learning, we must actively build conducive to learning to construct knowledge learning environment, take full advantage of the network, the establishment of public relations case database of exercises, the teacher's lesson plans, teaching plans, curricula, student reading lists for students linked to the Internet and other inquiries. At the same time, either to purchase teaching artists, public relations celebrity videos, you can also collect, collate public relations in recent years, the latest case, the information compiled, linked to the Internet for students to learn [5]. Rich learning content, to meet the different needs of students, to strengthen the students' motivation to learn. Therefore, teachers in teaching should be good at digging textbooks hidden emotional content, appropriate use of projection, music, video and other modern educational techniques to stimulate motivation to learn, so that students immersed in the beautiful art of enjoyment in order to obtain greater and more good teaching effect.

Sukhomlinski promote harmonious education, with special emphasis to make students have a rich spiritual life and spiritual needs through a variety of spiritual life, to ensure the comprehensive development of personality, to ensure the full performance of individual talent in order to make learning effective. Public participation in the mass media, making public the information to explain the meaning and significance of the reconstruction process, naturally spread their ideas to join internalization or strengthen [6]. Therefore, the need to strengthen the culture of quality education 
to enrich students' spiritual world. Cultural Quality Education is not the focus of the course, but the atmosphere; not to impart knowledge, but the influence of campus culture; not simply preaching and indoctrination, but the perception of cultural spirit, cultural traditions shower, imperceptibly, monasteries [7].

Traditional Chinese culture attaches particular importance to harmony thought Houdezaiwu. Therefore, the cultural quality of education, positive impact on students applying to enable students to learn from the rich nutrients from the Chinese traditional culture, through cultural and social development to deepen understanding, develop their correct outlook on life, ethics and values, so that students clear understanding of their historical responsibility. "Deep spiritual connotation and meaning of Utopia is the pursuit of ideals, the reality beyond, in the inner yearning and caring spirit. Spirit is no utopia, it is difficult to get out secularism in education, instrumentalism, molding doctrine misunderstanding." [ 8] cultural quality education must focus on helping people transcend its biological existence, the spiritual formation of a clear value-oriented, and create a people's spiritual world, people freed from immediate material interests and utilitarian values of bondage, to cultivate individuality, autonomy free citizenship, self-awareness, critical spirit, people continue to liberation from the established state out beyond a given variety of characters and make the educational process into a conscious person, since, for the process of self-creation, so Construction of complete self-educated, self-improvement.

Skate gold for the first time proposed a "positive emotional background principles of teaching" and stressed the need to create a harmonious learning atmosphere. In teaching, teachers should make use of modern educational technology freely regulatory advantages, will be converted into figurative language, visualization, and specific teaching content, vivid available to students, encourage students to emotional investment, to stimulate students' aesthetic desire. Such as teaching the traditional table of contents "blessing", teachers in the teaching process, the first four can change the appearance of the eyes or Xianglinsao, with the reproduced picture, so that students around the four screens expand the association and imagination, talk about your feelings of Xianglinsao such a big change, and to explore possible reasons for the formation of such a change. At this time, the students already have in mind a first perceptual and rational knowledge about the lesson, the lesson to learn more about their great help. At the same time, together with the focus on the content and presentation of affectionate reading, appropriate background music, and at this time interspersed Xianglinsao "I was a fool," the voice-over and the crowd indifferent expression, for the creation of this article to learn a good atmosphere, so students recognize the root causes of the tragic fate of Xianglinsao deepen hatred of the old society, and cherish the longing for a better life. After the study is completed, the teacher then screening of the film "blessing" to enable students to compare differences in text and video reading literature, students of comparative information screening capacity and reading ability [9].

Teaching method is a means to achieve teaching objectives, teaching methods to select the relationship to achieve the degree of teaching content. Zankov pointed out that when it comes to teaching methods and students' emotions will the field, touch the spiritual needs of the students, this teaching method can play a highly effective role. Lozanov believes traditional teaching underestimate the enormous human potential, ignore the role of unconscious mental activity and emotion in learning. Suggestopedia is the use of people may suggestive, emotional rendering emphasis on teaching and learning environment to stimulate personal psychological, create a strong motivation to learn, the full development of self, Sense and Sensibility achieve unity, unified conscious and unconscious functions functions, particularly those in mobilize the potential of the unconscious brain areas, so that students in a happy atmosphere, unconsciously accept the message. Teaching, teachers should make use of modern educational technology, refining a variety of educational materials from the social life, the use of pictures, models, film, theater, games and other visual means, to provide students with a wealth of image information to guide students to pay close attention to social concerns life, do conscientious life, careful people, to provide students with standards of ethical conduct, in order to encourage students into the correct cognitive behavior, students good habits, norms of behavior, so that students receive a good feeling in the atmosphere 
education.

Lenin said: "There is no 'human emotions' has never, nor can there be the pursuit of truth." Emotion is to promote knowledge, cognitive beliefs into the catalyst, any art can be said to be emotional art. Modern teaching materials at all levels, the students all permeated with ideological and moral education content, so every teacher in the use of modern educational technology at the same time, have the responsibility and obligation to strengthen emotional education, so that students emotional factors inherent released to enable students to establish norms of morality.

\section{Acknowledgements}

Fund Project: Chinese Association of Higher Education 2011 Special issue an interim evaluation results "Local Agricultural Colleges and Universities Research Quality Education and Evaluation of Student Development Mechanism". (Item Number: 2011HYZX037).

\section{References}

[1] Zhu Xiaoman. Outline of Emotional Education [M]. Beijing: People's Publishing House, 2007.

[2] Wang Haiyan, Shao Xiwu. modern teaching should make full use of modern information technology to strengthen the influence of the emotional high school students [J]. Modern intelligence, 2006 (2): 181-183.

[3] Xie Juan. Between Philosophy and Politics: Trend Technology Education [J]. Education], 2011 (12): 9-12.

[4] Yan Ming, Zhang Xiaoshu. Emotional Education: Carding and Introspection [J]. Education, 2005 (1): 103-104.

[5] Shaoxi Wu, Wang Haiyan, Jiang Xijuan. Based on Constructivist Theory Teaching Model of "public relations" [J]. Jilin College of Education, 2009 (9): 63-65.

[6] Zhang Shuyan, Zhao Jilun. Harmonious Society and emotional education [J]. Northeast Normal University (Philosophy and Social Sciences), 2008 (3): 32-35.

[7] Zhu Kongjun, Li Yanbao. culture and innovation of Talents [J]. Chinese university teaching, 2007 (9): 8-12.

[8] Hao Deyong. spiritual character of contemporary education and the pursuit of [J]. Higher Education Research, 2007 (5): 16-20.

[9] Wang Haiyan, Shao Xiwu. Modern teaching should make full use of modern information technology to strengthen the influence of the emotional high school students [J]. Modern intelligence, 2006 (2) 181-183. 